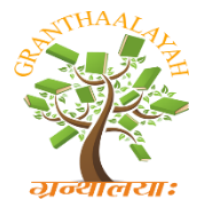

\author{
INTERNATIONAL JOURNAL OF R
GRANTHAALAYAH \\ A knowledge Repository
}

Science

\title{
LUNG CANCER - STATISTICAL ANALYSIS DATA IN A 5 YEAR PERIOD IN BITOLA, REPUBLIC OF NORTH MACEDONIA
}

\author{
Jihe Zhu ${ }^{1}$, Blagica Arsovska 1,2, Kristina Kozovska 1,3 \\ ${ }^{1}$ Faculty of Medical Sciences, University Goce Delchev, Shtip, Republic of Macedonia; \\ ${ }^{2}$ Institute of Biology, Faculty of Natural Sciences and Mathematics, Skopje, Republic of \\ Macedonia \\ ${ }^{3}$ Medicine Faculty, St. Cyril and Methodius University of Skopje, Republic of Macedonia
}

\begin{abstract}
Lung cancer is one of the most common and deadly malignancies in the world, which is characterized by uncontrolled division and growth of malignant cells in the pulmonary parenchyma. For the purposes of this paper was used data from the clinical hospital "Dr. Trifun Panovski" in the Municipality of Bitola, Republic of North Macedonia in the period of 2015-2019. The results show that the most of the cases are male with the leading age of about 55-64 years. However, the disease is becoming more common in the female population at a later age. Regarding the number of male patients treated in the Municipality of Bitola, it can be noted that the highest number of male patients was in 2018, and the lowest in 2017. Most female patients were treated in 2016 and the least in 2018. From the analysis of the Institute of Public Health, the highest number of male deaths in Bitola occurred in 2014 and the lowest in 2015 and 2018, among female patients, the highest number of deaths was in 2014, but the lowest in 2018. Death outcomes in Bitola represent about 6-7\% of total number of deaths in the Republic of North Macedonia.
\end{abstract}

Keywords: Cancer; Pulmonology; Lungs; Bitola; Prognosis; Statistics.

Cite This Article: Jihe Zhu, Blagica Arsovska, and Kristina Kozovska. (2020). "LUNG CANCER - STATISTICAL ANALYSIS DATA IN A 5 YEAR PERIOD IN BITOLA, REPUBLIC OF NORTH MACEDONIA." International Journal of Research - Granthaalayah, 8(2), 108-117. https://doi.org/10.29121/granthaalayah.v8.i2.2020.191.

\section{Introduction}

Lung cancer is a malignant disease characterized by the uncontrolled growth of abnormally mutated cells in the lung parenchyma of one or both lungs. It is considered to be a leading cause of death from malignant disease in men, and in women it is second after breast cancer. Lung cancer is roughly divided into non-small cell and small cell carcinoma which has a worse prognosis. Treatment and prognosis depend on the histologic type of cancer, the stage of diagnosis, and the patient's general health. 
Although initially asymptomatic, lung cancer is a condition with high-mortality. Most lung cancers are caused by carcinogens and tumor promoters inhaled by smoking cigarettes. The risk of developing cancer increases several times in active smokers and in chronically passive smokers. About $15 \%$ of lung cancers occur in people who have never smoked cigarettes, especially expressed in women that gives rise to doubts about the possible role of hormonal factors. The second factor comes from environmental and occupational factors such as air pollution, irradiation, asbestos, metals, etc. Genetic predisposition also plays a major role. Certain studies have also mentioned diet as a possible risk factor.

The basic histologic classification of invasive lung cancer is small cell and non-small cell. The term non-small cell lung cancer refers to a group of frequently observed pulmonary neoplasms most commonly associated with cigarette smoking and having the common feature of not responding to therapeutic protocols for small cell cancer. Non-small cell lung cancer has a higher histological sub-classification, ie the main types of non-small cell carcinoma are: adenocarcinoma, squamous cell carcinoma, adenoma squamous cell carcinoma, large cell carcinoma, carcinomas with pleomorphic elements and carcinoid tumors.

A small proportion of patients with lung cancer are initially asymptomatic, but some are diagnosed by chance on routine thoracic X-ray or CT scans. In some patients, the first symptoms occur only when the cancer has advanced to a stage that is unresectable. According to local tumor growth, some of the symptoms depend on peripheral versus central lung localization. For example, central and endobronchial localized tumors are manifested by common cough, hemoptysis, shortness of breath, stridor etc. Peripherally localized tumors can manifest as chest pain, cough, dyspnea and with symptoms of pulmonary abscess.

The modern therapeutic approach includes surgical treatment, radiotherapy treatment, adjuvant chemotherapy (for Stage-IB and Stage-II), symptomatic therapy (mainly with analgesics) and immunotherapy.

The prognosis of patients with lung cancer generally depends on several factors. The most important features mentioned are advanced stage during diagnosis, histological subtype of cancer, anatomical localization of potential metastases, as well as patient-dependent factors (general health, healthy lung condition, performance status). The prognosis for 5-year lung cancer survival for all stages together is about $14-16 \%$, and has not changed in the last 30 years. [1-7]

\section{Material and Methods}

The working methods used in this research are:

- Collection and processing of statistical and epidemiological data on the number of treated patients as well as the total hospital days achieved in the clinical hospital "Dr. Trifun Panovski " in the Municipality of Bitola (2015-2019).

- Collecting and analyzing data from the Center for Public Health - Bitola

- Data analyzation from State Statistical Office of the Republic of North Macedonia

- Further processing of statistics on the number of deaths of patients with respiratory tract cancer on the territory of the Republic of Northern Macedonia and in the Municipality of Bitola (2014-2018). 
The results are processed in detail, analyzed and statistically presented in the paper in tables, graphs and images.

\section{Results and Discussion}

Surveys of statistics in recent years indicate the highest number of male patients, with the leading age group being around 55-65 years, however, the disease is more common in the female population in advanced age. The number of deaths in the Bitola region accounts for less than $10 \%$ of the number of deaths at the level of the Republic of Northern Macedonia.

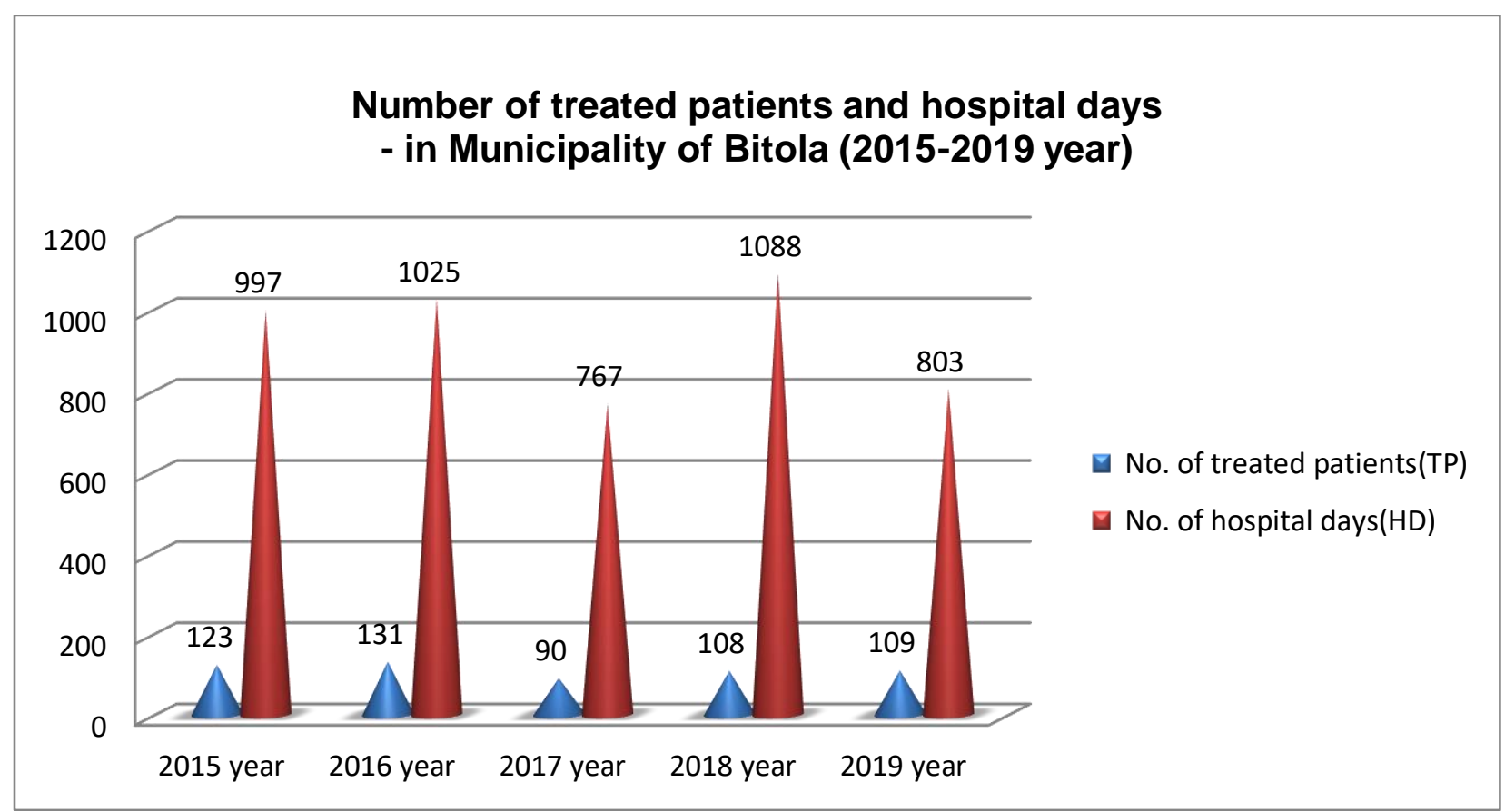

Scheme 1: Total number of treated patients (TP) and hospital days (HD) of patients with respiratory cancer in the Municipality of Bitola (2015-2019year)

The above scheme 1 summarizes the information on the total number of treated patients and achieved hospitalized days in the Municipality of Bitola in the period of 5 consecutive years (20152019). The same information shows that the total number of patients treated in the last 5 years (2015-2019) in Bitola has a descending character with the lowest number of patients treated in 2017 and the highest in 2016. The number of hospital days achieved is also the lowest in 2017, but the highest in 2018.

The number of hospital days and patients treated varies by sex and age. Accordingly, the number of hospital days achieved by male patients is the highest in 2018 and the lowest in 2017. The number of hospital days achieved by female patients is the highest in 2016 and the lowest in 2019. The group with the most accomplished hospital days are patients aged 55-64, although there are also a large number of patients aged 45-54 and 65-74 (Patients aged 65-74 have achieved the highest number of hospital days in 2017). The difference in the number of patients treated by age is similar to the number of hospitalized days. 


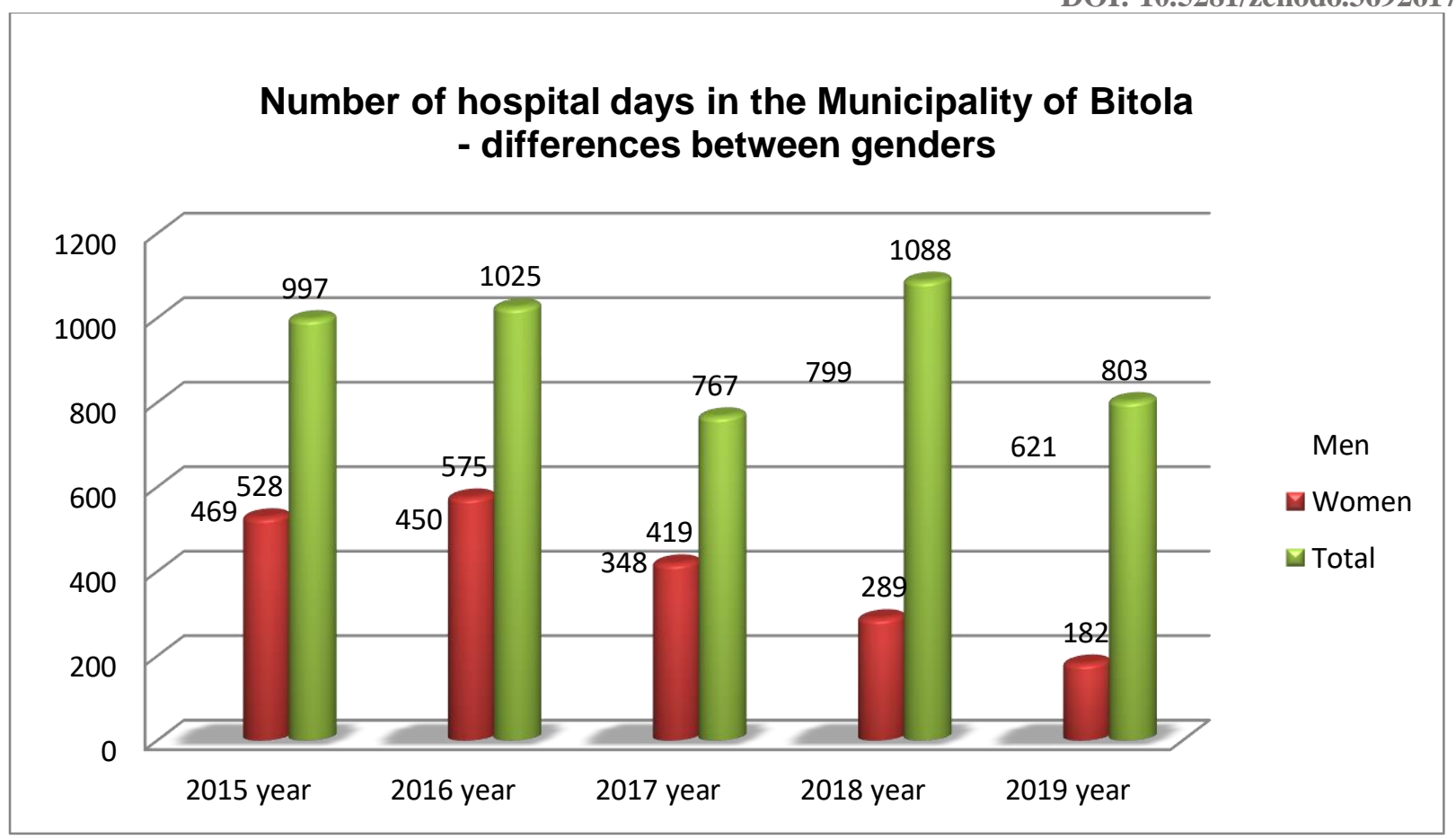

Scheme 2.1: Total number of hospital days of patients with respiratory cancer in the Municipality of Bitola (2015-2019year), differences between genders

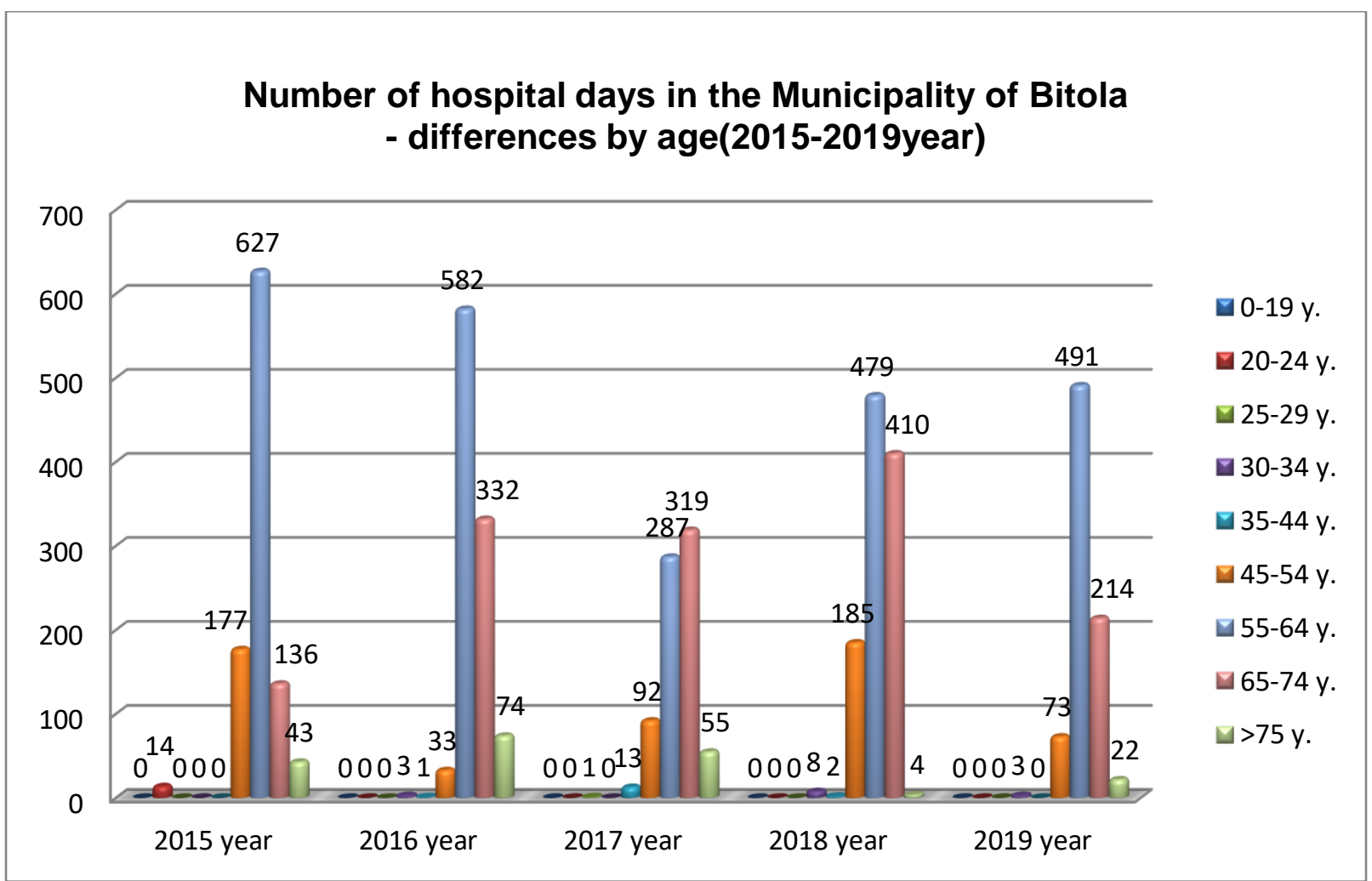

Scheme 2.2: Total number of hospital days of patients with respiratory cancer in the Municipality of Bitola(2015-2019year), differences by age 


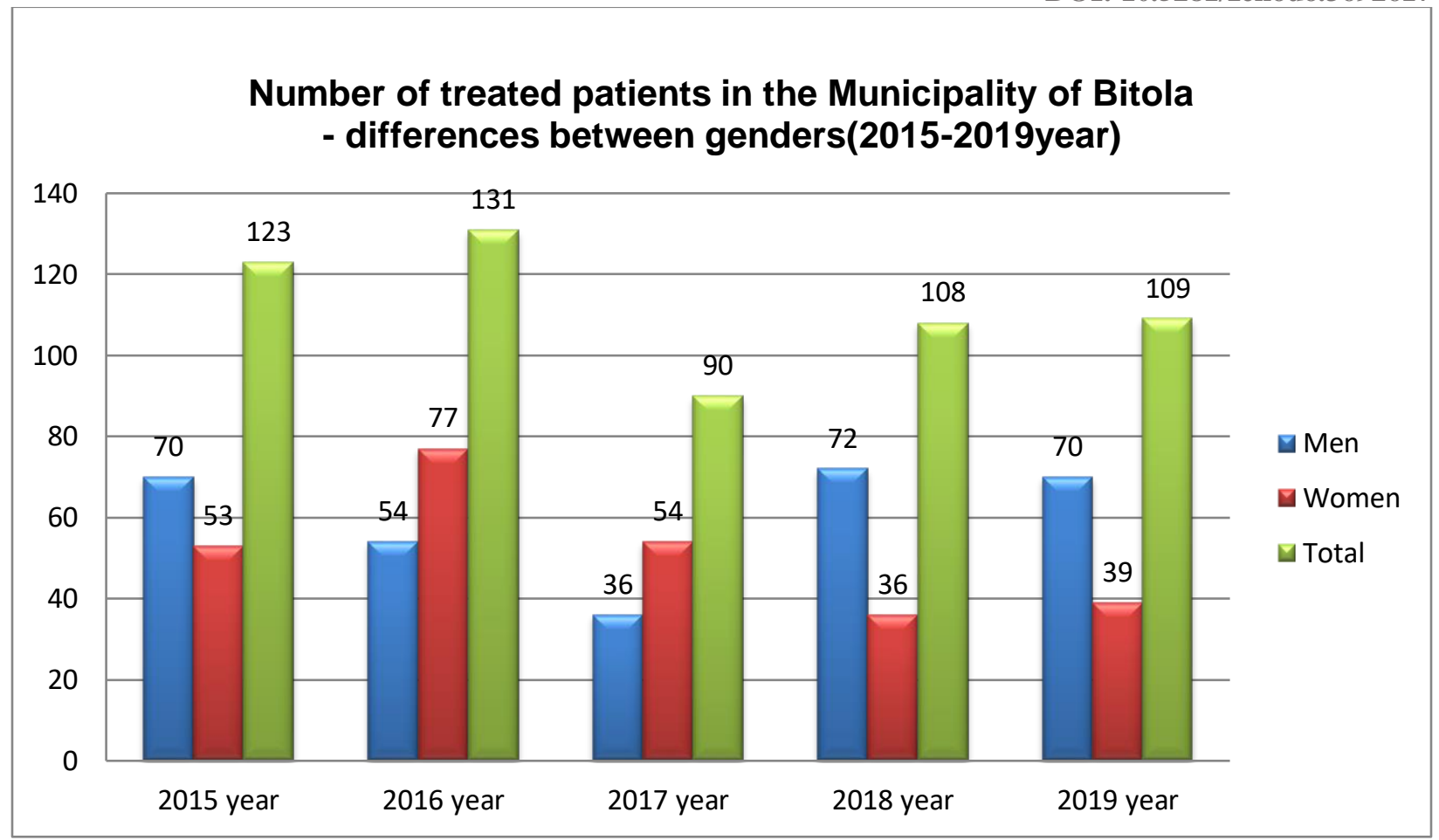

Scheme 3: Total number of treated patients with respiratory cancer in the Municipality of Bitola (2015-2019year), differences between genders

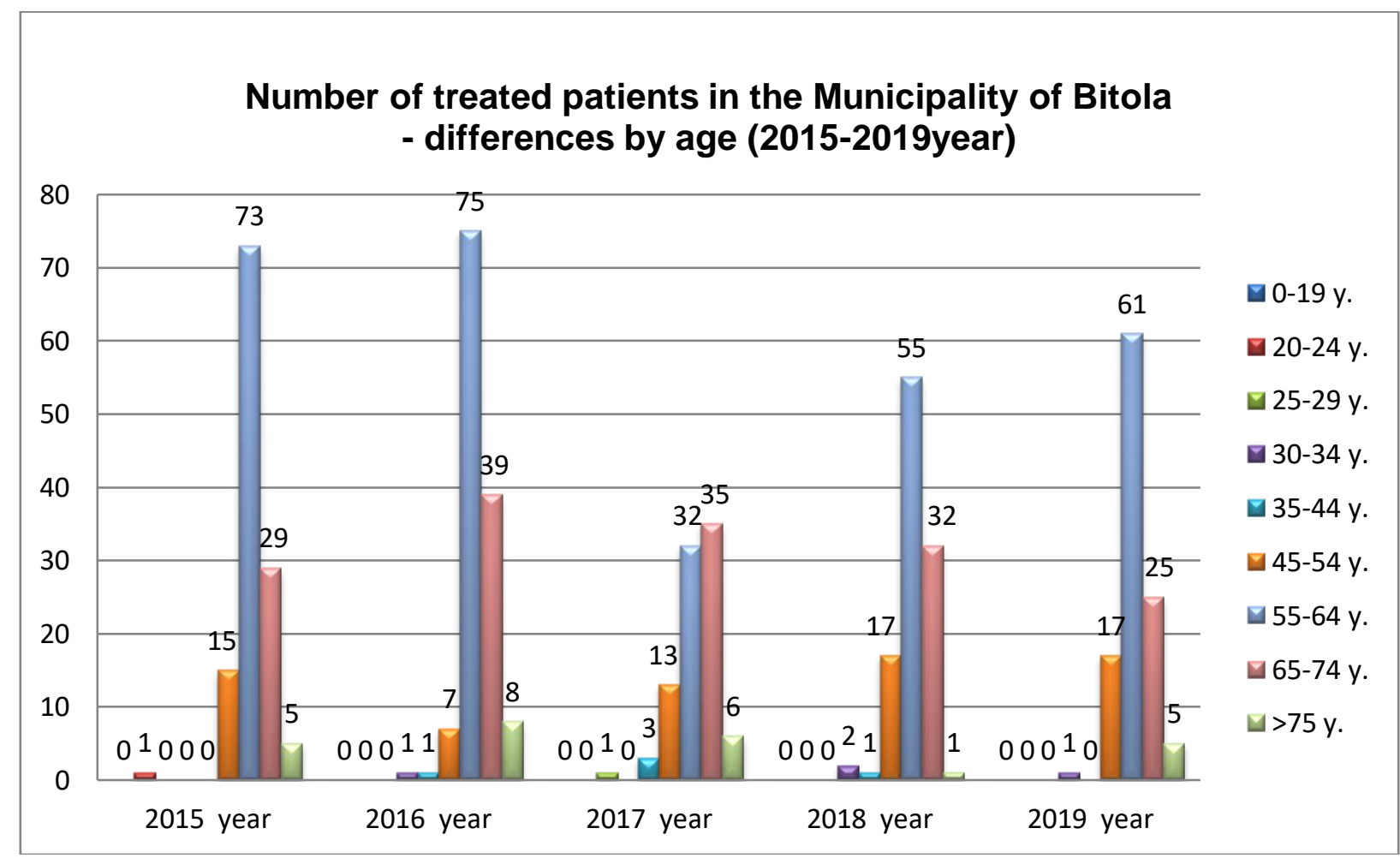

Scheme 3.1: Total number of treated patients with respiratory cancer in the Municipality of Bitola (2015-2019year), differences by age 


\section{Number of treated patients in the Municipality of Bitola - differences by diagnosis (2015 year)}

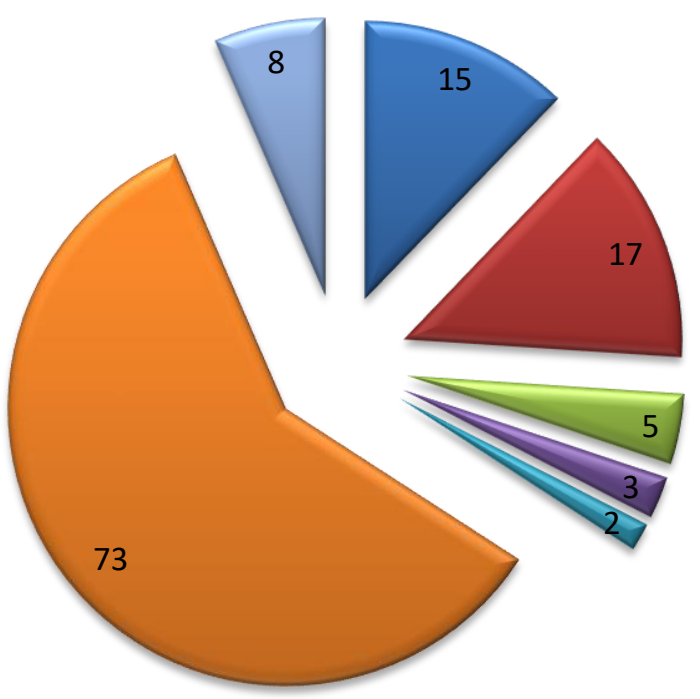

- $\mathrm{C} 32.9$

D 34.0

$\square$ C34.1

- C34.2

$\square \mathrm{C} 34.3$

$\square$ C34.9

$\square \mathrm{C} 38.4$

Scheme 4: Total number of treated patients with respiratory cancer in the Municipality of Bitola (2015 year), differences by diagnosis

\section{Number of treated patients in the Municipality of Bitola - differences by diagnosis (2016 year)}

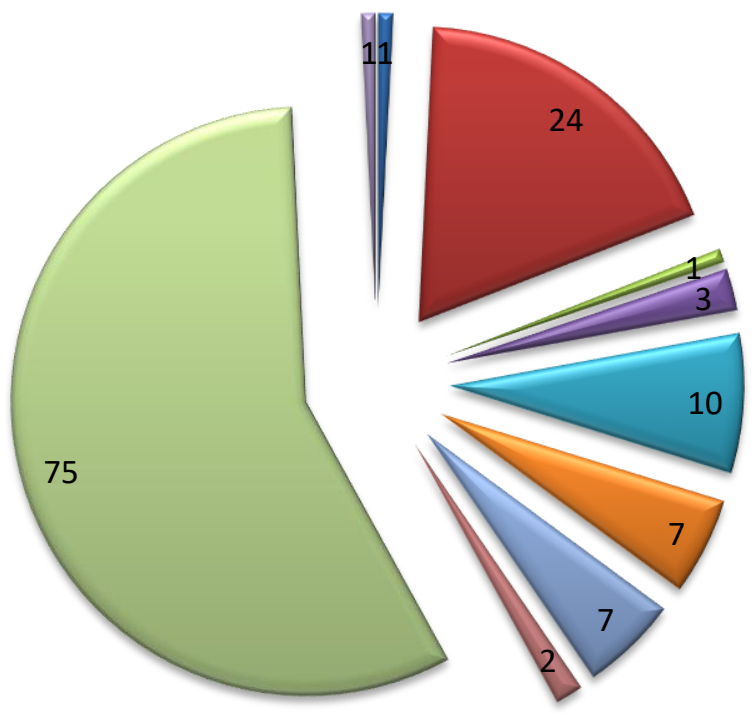

$\nabla C 32.8$

口C32.9

$\square$ C34

口 C34.0

$\square$ C34.1

C 34.2

$\square$ C34.3

$\square$ C34.8

$\square$ C34.9

$\square$ C38.4

Scheme 4.1: Total number of treated patients with respiratory cancer in the Municipality of Bitola (2016 year), differences by diagnosis 


\section{Number of treated patients in the Municipality of Bitola - differences by diagnosis (2017 year)}

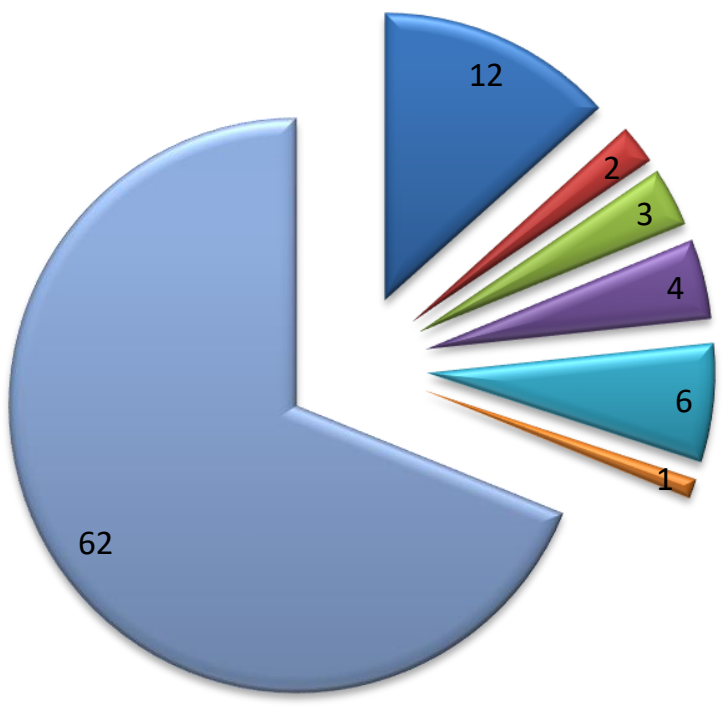

口 C32.9

口 $\mathrm{C} 34.0$

$\square$ C34.1

$\square$ C 34.2

$\square$ C34.3

$\square$ C34.8

$\square$ C 34.9

Scheme 4.2: Total number of treated patients with respiratory cancer in the Municipality of Bitola (2017 year), differences by diagnosis

\section{Number of treated patients in the Municipality of Bitola - differences by diagnosis (2018 year)}

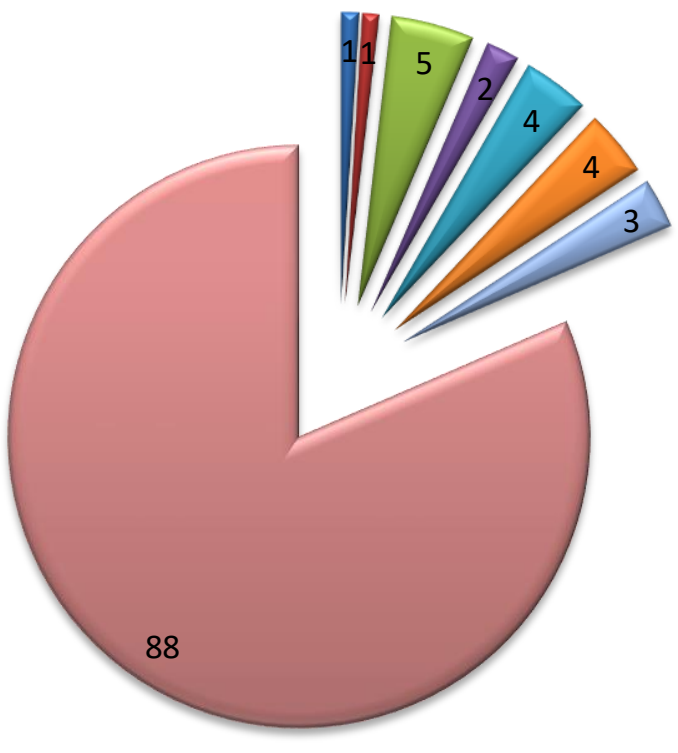

Scheme 4.3: Total number of treated patients with respiratory cancer in the Municipality of Bitola (2018 year), differences by diagnosis 


\section{Number of treated patients in the Municipality of Bitola - differences by diagnosis (2019 year)}

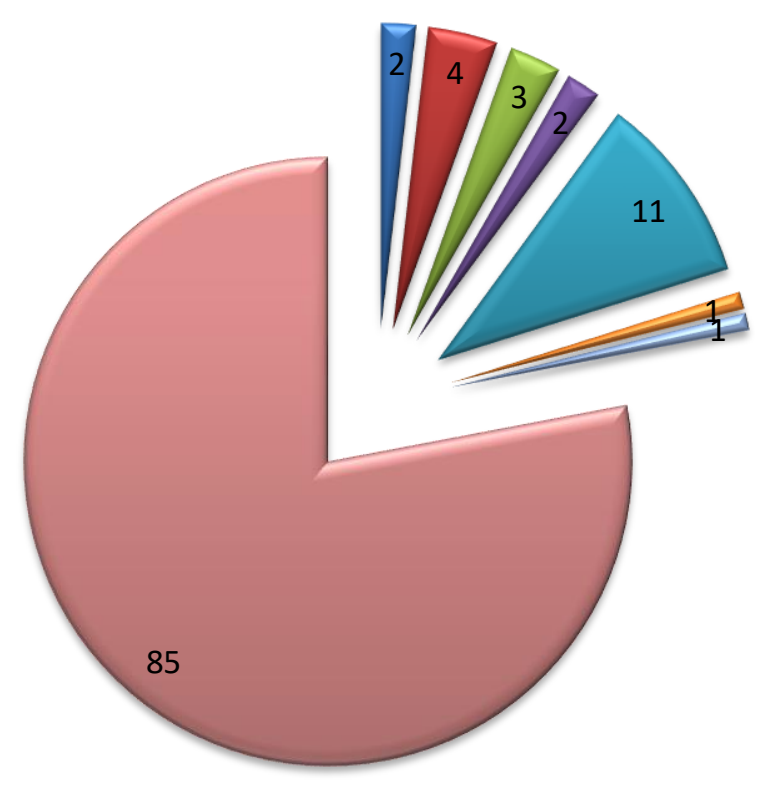

Scheme 4.4: Total number of treated patients with respiratory cancer in the Municipality of Bitola (2019 year), differences by diagnosis

Description of diagnoses according to ICD-10:

- C31.9 - Malignant accessory sinus neoplasm

- C32.0 - Malignant glottis neoplasm

- C32.3 - Malignant neoplasm of laryngeal cartilage

- C32.8 - Malignant neoplasm of the overlapping larynx

- C32.9 - Malignant neoplasm of the larynx

- C34 - Malignant neoplasm of bronchus and lung

- C34.0 - Malignant neoplasm of the main bronchus

- C34.1 - Malignant neoplasm of the upper lobe, bronchus, or lung

- C34.2 - Malignant neoplasm of middle lobe, bronchus, or lung

- C34.3 - Malignant neoplasm of the lower lobe, bronchus, or lung

- C34.8 - Malignant neoplasm of overlapping sites of bronchus and lung

- C34.9 - Malignant neoplasm of unspecified part of bronchus or lung

- C38.4 - Malignant neoplasm of pleura

From the above schemes (from scheme 4 to 4.4) it can be concluded that the most common diagnosis from which patients were treated in the Municipality of Bitola in the last 5 years (20152019) according to ICD-10 is C34.9 (Malignant neoplasm of unspecified part of bronchus or lung), regardless of the gender and age of the patients. 
Table 1: Total number of death outcomes of patients with respiratory cancer in the Republic of North Macedonia (RNM) and Municipality of Bitola (BT), in 2014 year.

\begin{tabular}{|c|c|c|c|c|}
\hline \multirow{2}{*}{ 2014 year } & \multicolumn{2}{|c|}{ RNM } & \multicolumn{2}{c|}{ BT } \\
\cline { 2 - 5 } Total & C34 & C38.4 & C34 & C38.4 \\
\hline M & 878 & 5 & 46 & 0 \\
\hline F & 693 & 2 & 35 & 0 \\
\hline
\end{tabular}

Table 2: Total number of death outcomes of patients with respiratory cancer in the Republic of North Macedonia (RNM) \& Municipality of Bitola (BT), in 2015 year.

\begin{tabular}{|c|c|c|c|c|}
\hline \multirow{2}{*}{ 2015 year } & \multicolumn{2}{|c|}{ RNM } & \multicolumn{2}{c|}{ BT } \\
\cline { 2 - 5 } Total & C34 & C38.4 & C34 & C38.4 \\
\hline M & 840 & 3 & 33 & 0 \\
\hline F & 671 & $/$ & 27 & 0 \\
\hline
\end{tabular}

Table 3: Total number of death outcomes of patients with respiratory cancer in the Republic of North Macedonia (RNM) \& Municipality of Bitola (BT), in 2016 year.

\begin{tabular}{|c|c|c|c|c|}
\hline \multirow{2}{*}{ 2016 year } & \multicolumn{2}{|c|}{ RNM } & \multicolumn{2}{c|}{ BT } \\
\cline { 2 - 5 } Total & C34 & C38.4 & C34 & C38.4 \\
\hline M & 905 & 13 & 41 & 0 \\
\hline F & 703 & 7 & 33 & 0 \\
\hline
\end{tabular}

Table 4: Total number of death outcomes of patients with respiratory cancer in the Republic of North Macedonia (RNM) \& Municipality of Bitola (BT), in 2017 year.

\begin{tabular}{|c|c|c|c|c|}
\hline \multirow{2}{*}{ 2017 year } & \multicolumn{2}{|c|}{ RNM } & \multicolumn{2}{c|}{ BT } \\
\cline { 2 - 5 } Total & C34 & C38.4 & C34 & C38.4 \\
\hline M & 800 & 5 & 43 & 0 \\
\hline F & 605 & 3 & 34 & 0 \\
\hline
\end{tabular}

Table 5: Total number of death outcomes of patients with respiratory cancer in the Republic of North Macedonia (RNM) \& Municipality of Bitola (BT), in 2018 year.

\begin{tabular}{|c|c|c|c|c|}
\hline \multirow{2}{*}{ 2018 year } & \multicolumn{2}{|c|}{ RNM } & \multicolumn{2}{c|}{ BT } \\
\cline { 2 - 5 } & C34 & C38.4 & C34 & C38.4 \\
\hline Total & 895 & 2 & 33 & 0 \\
\hline M & 700 & $/$ & 28 & 0 \\
\hline F & 195 & $/$ & 5 & 0 \\
\hline
\end{tabular}

Description of diagnoses according to ICD-10:

C34 - Malignant neoplasm of bronchus and lung

C38.4 - Malignant neoplasm of pleura 
Tables 1-5 show mortality statistics for patients with lung cancer at the level of RNM and the Municipality of Bitola. The differences in the total number of deaths in the Republic of Northern Macedonia vary between years (2014-2018). The highest number of deaths was in 2016 and the lowest in 2017. By gender differences, the highest number of male deaths was in 2016, and the lowest in 2017. Also for female patients, the highest number of deaths was in 2016, but the lowest in 2015 .

At the level of the Municipality of Bitola from 2014-2018 there was the highest number of total deaths from lung cancer in 2014, and the lowest in 2015 and 2018. By gender, the highest number of deaths among male patients was in 2014, and the lowest in 2015. Female patients had the highest number of deaths in 2014 and the lowest in 2018. Death outcomes in Bitola represent about 6-7\% of total of RSM.

\section{Conclusion}

Lung cancer is a rare disease and at the same time a global problem in the world. The role of smoking in the pathophysiological mechanism of cancer development has also been proven. Statistics at the level of the Republic of Northern Macedonia and the Municipality of Bitola show the highest frequency of occurrence in male patients, and in relation to age at most 45-75 years.

\section{References}

[1] DeVita, Hellman and Rosenberg (2008). Cancer: Principles \& Practice of Oncology,8th edition, Volume 1.

[2] Thao P. Dang \& David P. Carbone (2008). Lung cancer: Molecular Biology of Lung Cancer

[3] David S. Schrump, Giuseppe Giaccone, Christopher Kelsey \& Lawrence B. Marks (2008). Lung cancer: Non-small Cell Lung Cancer

[4] Dennis Kasper, Anthony Fauci, Stephen Hauser, Dan Longo, J. Larry Jameson and Joseph Loscalzo (2018). Harrison's principles of internal medicine,20th edition

[5] Joshua Carson \& David J. Finley. (2011); Lung Cancer Staging: An Overview of the New Staging System, and Implications for Radiographic Clinical Staging; 46(3): 187-193.

[6] Statistics from the Center for Public Health of the Municipality of Bitola

[7] Statistics from the State Statistical Office of the Republic of Northern Macedonia

*Corresponding author.

E-mail address: tongdatang-tcm $@$ hotmail.com 